\title{
A avaliação da transparência ativa e passiva das universidades públicas federais do Brasil à luz da Lei de Acesso à Informação
}

\author{
Melina Pompeu de Lima ${ }^{1}$ \\ Márcio Moutinho Abdalla ${ }^{2}$ \\ Leonel Gois Lima Oliveira ${ }^{3}$
}

${ }^{1}$ Centro Federal de Educação Tecnológica Celso Suckow da Fonseca (CEFET-RJ), Nova Iguaçu - RJ, Brasil

${ }^{2}$ Universidade Federal Fluminense (UFF), Volta Redonda - RJ, Brasil

${ }^{3}$ Centro Universitário Christus (Unichristus), Fortaleza - CE, Brasil

Este estudo teve como objetivo avaliar se as 63 Universidades Federais do Brasil são transparentes no que tange aos quesitos transparência ativa e passiva estipulados pela Lei de Acesso à Informação (LAI). Para isso, utilizou-se da revisão de literatura, levantamento das universidades federais, utilização de parâmetros normativos, formulação dos pedidos de informação, construção de instrumentos de pontuação e definição de métodos de ranqueamento. Os resultados de cada transparência foram positivos, mas assimétricos, revelando um comprometimento maior das universidades com a transparência passiva, dada uma alta porcentagem de respostas dentro da população estudada (71\%), em detrimento da transparência ativa (56\%). No entanto, em cada uma das etapas foram detectados obstáculos próprios, como a interpretação errônea do que foi perguntado ou o envio de inúmeros arquivos, em formatos variados, complexos e não amigáveis, no caso da transparência passiva. Já na aferição da transparência ativa, ficou óbvia a existência de descumprimento em relação às orientações utilizadas como parâmetro, o que gerou uma gama de dados heterogêneos, cujo tratamento exigiu a construção de instrumentos apropriados.

Palavras-chave: transparência pública, Lei de Acesso à Informação, universidades federais 


\section{La evaluación de la transparencia activa y pasiva de las universidades públicas federales en Brasil a la luz de la Ley de Acceso a la Información.}

Este estudio tuvo como objetivo evaluar si las 63 Universidades Federales de Brasil son transparentes con respecto a los requisitos de transparencia activa y pasiva estipulados por la Ley de Acceso a la Información (LAI). Para esto se utilizó la revisión de literatura, encuestas de universidades federales, uso de parámetros normativos, formulación de solicitudes de información, construcción de instrumentos de calificación y definición de métodos de clasificación. Los resultados de cada transparencia fueron positivos, pero asimétricos, revelando un mayor compromiso de las universidades con la transparencia pasiva, dado un alto porcentaje de respuestas dentro de la población estudiada (71\%), en detrimento de la transparencia activa (56\%). Sin embargo, en cada una de las etapas, se detectaron obstáculos específicos, como la mala interpretación de lo que se solicitó o el envío de numerosos archivos, en formatos variados, complejos y poco amigables, en el caso de la transparencia pasiva. En la medición de la transparencia activa, el incumplimiento de las pautas utilizadas como parámetro fue obvio, lo que generó una gama de datos heterogéneos, cuyo tratamiento requirió la construcción de instrumentos apropiados.

Palabras clave: transparencia pública, Ley de Acceso a la Información, universidades federales

\section{The Assessment of Active and Passive Transparency of Federal Public Universities in Brazil in the light of the Access to Information Law.}

This study aimed to assess whether the 63 Federal Universities of Brazil are transparent regarding the active and passive transparency requirements stipulated by the Access to Information Law (LAI). For this, were used a literature review, survey of federal universities, use of normative parameters, formulation of information requests, construction of scoring instruments and definition of ranking methods. The results of each transparency were positive, but asymmetric, revealing a greater commitment by universities to passive transparency, given a high percentage of responses within the population studied (71\%), to the detriment of active transparency (56\%). However, in each of the stages, specific obstacles were detected, such as the erroneous interpretation of what was asked or the sending of numerous files, in varied, complex and unfriendly formats, in the case of passive transparency. In the measurement of active transparency, non-compliance with the guidelines used as a parameter was obvious, which generated a range of heterogeneous data, the treatment of which required the construction of appropriate instruments.

Keywords: public transparency, Access to Information Act, federal universities 


\section{Introdução}

As universidades públicas federais brasileiras são transparentes? Esse questionamento simples pode suscitar outros, como: sob qual aspecto são transparentes? Quais parâmetros podem demonstrar essa transparência? Considerar essas perguntas adicionais é importante quando se investiga o tema transparência, pois a literatura sobre o assunto demonstra um atual contexto internacional de abertura dos governos a um minucioso exame público. Ademais, há que se considerar a existência de tipos de transparência, com diversas definições e classificações, e normas legais associadas, que estabelecem critérios de parametrização, além do uso do termo como conceito basilar a uma boa governança pública. Esses fatores associados influenciam governos em todo o mundo e, por conseguinte, suas respectivas estruturas burocráticas.

Essa questão é relevante, pois instituições mais transparentes podem auxiliar a elevar a confiança em governos (TOLBERT; MOSSBERGER, 2006), o que é extremamente importante em tempos nos quais a frustação com a democracia parece ser um sentimento comum em várias nações, levando a crises de confiança nos governos e na legitimidade da forma pela qual os mesmos são conduzidos ao poder, segundo dados do relatório Índice de Transformação, publicado pela Fundação Bertelsmann, da Alemanha (FARIZA, 2018).

Ademais, a indagação inicial pode demonstrar a existência de variabilidade de transparência dentro de estruturas burocráticas governamentais, dado que existe "heterogeneidade do nível de abertura entre órgãos e entidades da administração pública federal" (SILVA et al., 2014, p. 28).

Entretanto, tratar sobre transparência exige a correta compreensão do termo, muitas vezes entendido como algo óbvio e simples, ou implícito (MICHENER; BERSH, 2011), no sentido equivocado de que a transparência pode ser imediatamente reconhecida quando vista, sem o aprofundamento necessário em relação ao seu aspecto conceitual. De acordo com Hood (2006), o termo transparência foi associado a diversos significados ao longo da história, até seu uso ser relacionado a política e governo, um sentido moderno, consolidado no século 20.

Assim, qualquer exame mais aprofundado requer cuidados em estabelecer qual (ou quais) aspecto(s) ou sentido(s) da transparência será(ão) analisado(s), dado que o termo adquiriu, ao longo dos anos, significado multidimensional e atrelado a diversas discussões, entre as quais sobre governo aberto (YU; RoBINSON, 2012) e governança 
pública (Zuccolotto; TeIXEIRA, 2019). Nessas duas hipóteses, transparência não aparece sozinha, mas constitui um pilar, entre outros, sobre o qual se sustenta um governo aberto ou se constrói uma governança pública.

Dentro do uso político delimitado por Hood (2006), um dos possíveis sentidos de transparência consiste no maior acesso às informações públicas, ao que Heald (2006) denomina "transparência horizontal para dentro", um conceito aplicável aos casos que envolvem leis de acesso à informação. No Brasil, o direito de acesso à informação pública era previsto desde a promulgação da Constituição Federal de 1988 (CF/88). No entanto, a materialização desse direito aconteceu apenas mais de duas décadas depois, com a Lei de Acesso à Informação (LAI) - Lei Federal nº 12.527/2011 (POLÍZIO JÚNIOR, 2015).

Apesar de o alicerce da LAI não residir apenas na CF/88, "mas igualmente em leis aprovadas nos anos 1990 e 2000” (MICHENER; CONTRERAS; NISKIER, 2018, p. 612), sua inovação reside em prever, ao longo de seus 47 artigos, duas iniciativas de transparência: ativa e passiva. Isso significa, respectivamente, que as informações poderão ser disponibilizadas de maneira proativa pelo governo, preferencialmente em portais institucionais na web (transparência ativa), ou, caso não estejam, poderão ser solicitadas por qualquer pessoa, a qualquer momento e sem justificativa (transparência passiva) (BRASIL, 2011).

Para Bairral, Silva e Alves (2015, p. 645), a LAI iniciou "um ciclo de mudanças na relação cidadão/gestor público", pois determinou “a divulgação (ativa ou via solicitação), e não o sigilo, como norma geral para a informação pública, envolvendo o fornecimento de dados em uma linguagem acessível e sem barreiras técnicas". No entanto, conforme apontamento contido na pesquisa de Lima (2018), os estudos desenvolvidos após os cinco anos de promulgação da LAI priorizam municípios, ou grupos de municípios de um estado ou de uma região, ou órgão municipais. O próprio Poder Executivo federal, principal indutor de todo esse processo de governo aberto, transparência e acesso à informação, não é incluído como objeto principal dos estudos envolvendo transparência e LAI (LIMA, 2018). Essa dominância dos governos locais nas pesquisas ainda persiste, com um número de publicações bem superior quando comparamos com a União. Em levantamento realizado no site Google Scholar, com o uso dos termos "lei de acesso à informação" e "transparência pública", no período de 2019 a 2020, esta pesquisa descobriu que, dos 232 artigos resultantes, apenas 15 pesquisavam órgãos da União. 
Esse cenário torna-se ainda mais relevante quando se leva em consideração a diversidade de órgãos públicos do Poder Executivo federal e a sua importância estratégica no que diz respeito à transparência. Setores como a educação pública de nível superior, por exemplo, são primordiais no desenvolvimento sustentável da nação em longo prazo e recebem o aporte anual de recursos na ordem de bilhões de reais.

Nesse sentido, dos 15 artigos mencionados anteriormente, 12 foram estudos de caso abordando uma universidade ou um pequeno grupo de instituições federais de ensino superior, seja analisando um aspecto da LAI ou relacionando-a a alguma questão institucional (Afonso; Vianna; Mattos, 2019; Gama; Mattos; Aguiar, 2019; Guerra; Carvalho, 2019; Maciel et al., 2019; Moura; GonÇAlves, 2019; PeCegueiro; Cordeiro, 2019; Rosa; Baptaglin, 2019; Rosa; Cabero, 2019; Rodrigues; Resende; CARneiro, 2019; Mendes Vieira; Pegoraro; SÂmara Visentini, 2020; VIEIRA; DAHER, 2020; WeIZENMANN; TEChio; Pinto, 2020).

Como comentado, são poucos estudos, quando contextualizamos ao fato de que a educação de nível superior vem se reestruturando nos últimos dez anos, por meio da ampliação do ensino a distância (EAD) e pela criação de programas como o Programa de Reestruturação das Universidades Federais (REUNI), em 2010. A ideia desse programa foi promover a expansão da rede federal de educação superior, incluindo as universidades federais, tanto em termos físicos quanto acadêmicos e pedagógicos (LEHER, 2013), com o respectivo aumento de recursos financeiros. De fato, os recursos financeiros aumentaram nos anos seguintes, mas não se mantiveram; os anos subsequentes a 2013 registram um declínio nos recursos, em meio a situações recorrentes de cortes e contingenciamentos (MoReno, 2018; Novelino, 2020). Apesar disso, em 2017 os repasses do governo às universidades federais ultrapassaram os seis bilhões de reais, mesma tendência de 2018.

Portanto, analisar a transparência em uma área que recebe recursos da ordem de seis bilhões não é apenas uma questão de divulgação de informações. Configura-se em um estudo de extrema relevância para a avaliação do cumprimento de normas como a LAI, criadas justamente para possibilitar e facilitar o acesso e exame pela sociedade dos dados governamentais, incluindo os gastos do orçamento da União. Para Michener, Contreras e Niskier (2018, p. 611), "a ausência de análises abrangentes publicadas sobre o funcionamento da Lei $\mathrm{n}^{\circ} 12.527 / 11$ representa uma significativa lacuna no entendimento da administração pública no Brasil”. 
Assim, esta pesquisa mostra-se relevante por objetivar a avaliação da transparência (ativa e passiva) de todas as 63 universidades públicas federais brasileiras, ou seja, toda uma população de um setor governamental. A metodologia consistirá em duas etapas, desenvolvidas paralelamente: análise dos portais dessas universidades, por meio de um guia publicado pela Controladoria Geral da União (CGU), e o envio de formulários de solicitação de informação por meio do portal E-SIC. Ambas serão oportunamente detalhadas na seção adequada.

\section{Revisão de literatura: as dimensões da transparência e a Lei de Acesso à Informação (LAI)}

\subsection{Dimensões da transparência}

As pesquisas sobre transparência inferem-lhe um conceito amplo, incerto, muitas vezes interpretado como algo simples e óbvio, quando na verdade não é. Zuccolotto, Teixeira e Riccio (2015, p. 139) apontaram que essa situação "leva a transparência a um alongamento conceitual e a um neologismo impreciso e incomunicável", apesar do uso crescente do termo na literatura. Segundo Michener e Bersh (2011, p. 1), “essa efervescência acadêmica, no entanto, não foi sustentada por nenhuma compreensão coletiva da transparência, e muito menos por qualquer debate sobre o que constitui a transparência, o que não é e como avaliar sua qualidade". Por não bastar disponibilizar o conteúdo, é recorrente a introdução de parâmetros que avaliem o nível de transparência como, por exemplo, o Ranking da Transparência para o Poder Judiciário promovido pelo Conselho Nacional de Justiça (CNJ) (CONSElHo NACiOnAl DE JustiçA, 2018). Nessa seara, além dos autores supracitados, outros, como Yazigi (1999), Heald (2006), Ball (2009) e Meijer, Curtin e Hillebrandt (2012), envidaram esforços para estabelecer parâmetros que norteassem os estudos na área de ciências humanas e sociais, conforme sintetizado no Quadro 1. 


\section{Quadro 1 - Levantamento dos conceitos e contextos da transparência}

\begin{tabular}{|c|c|}
\hline Autores & Conceitos e contextos da transparência \\
\hline Yazigi (1999) & $\begin{array}{l}\text { Diferencia pioneiramente (antes da promulgação da LAI no Brasil) o entendimento } \\
\text { de que a transparência pode ser ativa ou passiva conforme o acesso dos cidadãos a } \\
\text { informações pertinentes à performance de funções públicas. Há a variação de postura } \\
\text { conforme a proatividade na disponibilidade da informação: o Estado (transparência } \\
\text { ativa) e o cidadão (transparência passiva). }\end{array}$ \\
\hline Heald (2006) & $\begin{array}{l}\text { É um conceito multifacetado, tendo quatro direções e quatro variedades. As direções } \\
\text { associam-se aos benefícios e custo da transparência. As variedades seriam as } \\
\text { consequências, os resultados das análises das transparências. Os tipos são vertical, } \\
\text { com as direções para cima (condutas e resultados são observados pelos superiores } \\
\text { hierárquicos) ou para baixo (quando as condutas e resultados dos governantes são } \\
\text { observadas pelos governados); ou horizontal, com as direções para fora (quando o } \\
\text { subordinado hierárquico observa para além da organização) ou para dentro (quando } \\
\text { os que estão fora da organização observam aquilo que ocorre em seu interior). }\end{array}$ \\
\hline Ball (2009) & $\begin{array}{l}\text { A transparência relaciona-se a determinados atributos que fornecem três metáforas. A } \\
\text { primeira considera a transparência como um valor público adotado pela sociedade } \\
\text { para combater a corrupção. Na segunda, transparência é sinônimo de abertura de } \\
\text { decisões por parte da sociedade, governos e organizações sem fins lucrativos. Por fim, } \\
\text { a terceira metáfora enquadra transparência como uma ferramenta complexa, de boa } \\
\text { governança em programas, políticas, organizações e nações. }\end{array}$ \\
\hline $\begin{array}{c}\text { Michener e } \\
\text { Bersch (2011) }\end{array}$ & $\begin{array}{l}\text { A transparência é classificada em duas dimensões. A primeira é a visibilidade da } \\
\text { informação, que consiste em sua plenitude e na probabilidade de ser encontrada. A } \\
\text { capacidade de inferência é a segunda e se interliga com à qualidade da informação ou } \\
\text { dados. Se os dados são confusos, equivocados, ambíguos, eles põem em questão a } \\
\text { habilidade de fazer inferências a partir de tais informações e, consequentemente, gerar } \\
\text { dúvidas sobre o que foi divulgado. }\end{array}$ \\
\hline $\begin{array}{l}\text { Meijer, Curtin } \\
\text { e Hillebrandt } \\
\quad(2012)\end{array}$ & $\begin{array}{l}\text { Enfatiza a visibilidade na transparência, pois significa a possibilidade de abertura em } \\
\text { termos de informação, de acesso para que o cidadão veja o que o governo está } \\
\text { fazendo. }\end{array}$ \\
\hline $\begin{array}{l}\text { Zuccolotto, } \\
\text { Teixeira e } \\
\text { Riccio }(2015)\end{array}$ & $\begin{array}{l}\text { A transparência pode ser estudada por sete perspectivas: orçamentária; contábil; } \\
\text { institucional ou organizacional; social ou cívica; do processo licitatório; de contratos } \\
\text { e convênios; e midiática. }\end{array}$ \\
\hline
\end{tabular}

Fonte: Elaboração pelos autores.

Zuccolotto e Teixeira (2019, p.7) afirmam que, "independentemente da área estudada, o debate sobre transparência tem se tornado um tema central na agenda de quase todas as organizações, sejam elas públicas ou privadas, grandes ou pequenas", razão pela qual a transparência é apontada como condição fundamental no discurso público sobre boa governança. Neste ponto, ressalta-se o papel da transparência como um dos pilares do governo aberto, que possibilitou, por exemplo, nos Estados Unidos a instrução para as agências governamentais se tornarem mais transparentes, participativas e colaborativas. O objetivo dessa agenda era criar um nível sem precedentes de abertura no governo, para garantir a confiança pública, fortalecer a democracia e promover a eficácia e eficiência do governo (MCDERMOTT, 2010).

No cenário brasileiro, o Decreto $n^{\circ} 9.203 / 2017$, que dispõe sobre a política de governança da administração pública federal direta, autárquica e fundacional, enumera, 
em seu artigo terceiro, seis princípios da governança pública, entre os quais a transparência (BRASIL, 2017a). O mesmo decreto também inclui a comunicação aberta, voluntária e transparente como uma das diretrizes de governança pública nas instituições brasileiras, com o objetivo de promover a divulgação das atividades e dos resultados da organização, fortalecendo o acesso público à informação. Dessa forma, percebe-se que o decreto reforça "o compromisso com a transparência ativa (voluntária) e o acesso público à informação", contendo uma "síntese de recomendações amplamente difundidas nas organizações que tratam do tema" (BRASIL, 2018, p. 54). Portanto, evidencia o pressuposto de que a informação mantida por um governo é um ativo nacional, um recurso econômico valioso. E, como tal, não deve ser gerenciada em segredo, subutilizada ou mesmo negada sem uma justificativa fundamentada. Afinal, o governo detém dados e informações sobre si mesmo, a economia e a própria sociedade como um todo, tanto do passado quanto do presente. Um fluxo aberto de informação entre o governo e o público é encarado como primordial ao desenvolvimento de uma sociedade democrática (MCDERMOTT, 2010; MARIÑEZ NAVARRO, 2012).

\subsection{Lei de Acesso à Informação: transparências ativa e passiva}

A Lei de Acesso à Informação (LAI), com seus quarenta e sete artigos distribuídos em seis capítulos, foi criada com o objetivo de regular o acesso às informações públicas, conforme previsto na $\mathrm{CF} / 88$. Os primeiros três capítulos do regramento concentram-se, respectivamente, em disposições gerais; no acesso à informação e à sua divulgação - com instruções sobre o que deve ser obrigatoriamente divulgado pelos órgãos públicos -; e nos procedimentos do pedido, ou seja, o modo de fazer um pedido de acesso, solicitar informações. Dessa forma, na legislação encontram-se claramente discriminadas as duas possibilidades de se obter informações junto a um órgão público e, portanto, de transparência pública: ativa e passiva.

Para Silva e Bruni (2019), essa divisão do estudo da transparência em passiva e ativa não é somente didática, mas também procedimental. "Enquanto na transparência ativa as informações são disponibilizadas por interesse do gestor público ou por imposição legal de dados obrigatórios", na transparência passiva o ente público tem de estar preparado para responder a qualquer solicitação da sociedade, desde que tal solicitação não esteja sujeita a sigilo (SILVA; BRUNI, 2019, p. 418). 
O Quadro 2 apresenta as distinções entre os dois tipos de transparência previstos na LAI.

\begin{tabular}{|c|c|c|}
\hline \multirow{2}{*}{ Característica } & \multicolumn{2}{|c|}{ LAI } \\
\hline & Transparência ativa & Transparência passiva \\
\hline Iniciativa da informação & Administração pública (Art. $\left.8^{\circ}\right)$ & Qualquer interessado (Art. 10) \\
\hline Forma de acesso & $\begin{array}{l}\text { Internet, por meio do site da } \\
\text { instituição governamental (Art. } 8^{\circ} \text {, } \\
\left.\S 2^{\circ}\right) \text {. }\end{array}$ & $\begin{array}{l}\text { Serviço de Informação ao Cidadão } \\
\text { (SIC), que pode estar disponível pela } \\
\text { internet (e-SIC) ou de modo } \\
\text { presencial no órgão (Art. } 9^{\circ} \text {, I; Art. } \\
10, \S 2^{\circ} \text { ). }\end{array}$ \\
\hline Conteúdo da informação & $\begin{array}{l}\text { Divulgação de um conteúdo mínimo } \\
\text { previsto na LAI, além de } \\
\text { informações típicas do órgão (Art. } \\
8^{\circ}, \S 1^{\circ} \text {. }\end{array}$ & $\begin{array}{l}\text { Qualquer informação solicitada pelo } \\
\text { interessado, pertinente ao escopo do } \\
\text { órgão }\left(\text { Art. } 8^{\circ}\right) \text {. }\end{array}$ \\
\hline Tempo de divulgação & Tempo real & $\begin{array}{l}\text { Imediatamente, quando disponível, } \\
\text { ou em até } 20 \text { dias, prorrogáveis por } \\
\text { mais } 10 \text { dias }\left(\operatorname{artigo} 11, \S \S 1^{\circ} \text { e } 2^{\circ} \text { ). }\right.\end{array}$ \\
\hline
\end{tabular}

Fonte: Adaptado de Silva e Bruni (2019).

No que tange à transparência ativa, o artigo $8^{\circ}$ informa que "é dever dos órgãos e entidades públicas promover, independentemente de requerimentos, a divulgação em local de fácil acesso, no âmbito de suas competências, de informações de interesse coletivo ou geral por eles produzidas ou custodiadas". Essas informações são constituídas por, no mínimo: o registro das competências e estrutura organizacional, endereços e telefones das respectivas unidades e horários de atendimento ao público; de quaisquer repasses ou transferências de recursos financeiros; e das despesas; além de informações concernentes a procedimentos licitatórios, inclusive os respectivos editais e resultados, bem como a todos os contratos celebrados; e dados gerais para o acompanhamento de programas, ações, projetos e obras de órgãos e entidades; e respostas a perguntas mais frequentes da sociedade (BRASIL, 2011).

Nesses termos, a transparência ativa caracteriza-se pela divulgação de informações públicas de forma proativa pelos governos, sejam eles de qualquer esfera. Nessa forma de transparência, as informações são disponibilizadas espontaneamente, de preferência por meio de portais governamentais. Segundo Raupp e Pinho (2016, p. 290), "transparência ativa é aquela em que a divulgação de informações ocorre como uma iniciativa da entidade governamental, independentemente do pedido (...)". Obviamente, apenas tornar a informação disponível não significa que o órgão público está sendo 
transparente, visto que a informação recebida pelos cidadãos pode estar desatualizada, dispersa pelo site ou simplesmente incompreensível, do ponto de vista do usuário.

Dessa forma, a fim de cumprir com a lei e reunir, em um único espaço virtual, as informações obrigatórias de um órgão público federal, o Poder Executivo federal operacionalizou a questão da transparência ativa por meio de uma seção específica denominada Acesso à Informação, criada nos sites dos órgãos federais para divulgar as informações de interesse geral e de publicação obrigatória. Essa seção teria nomenclatura padronizada e conteúdo pertinente, a fim de facilitar o acesso da sociedade a essas informações de forma mais rápida, ágil e fácil (CRUZ; SILVA; SPINELLI, 2016).

Ademais, no que diz respeito a essa nova seção, a própria Secretaria de Transparência e Prevenção da Corrupção (STPC) da CGU desenvolveu um guia, a fim de orientar a disponibilização do conteúdo dessa área nos sites governamentais (BRASIL, 2017b). Esse guia contém diretrizes em consonância com a LAI e deve ser observado por todos os órgãos e entidades da esfera federal, sendo atualizado periodicamente, com a última versão publicada em fevereiro de 2019.

A respeito dos requisitos de transparência passiva constantes na LAI, no âmbito da União foi providenciada a implantação do Serviço de Informações ao Cidadão (SIC). Esse serviço conta com uma estrutura física instalada na sede dos órgãos. Dessa forma, em local de fácil acesso e devidamente identificado, servidores atendem presencialmente aos solicitantes, seja prestando informações ao interessado de forma imediata, quando possível, ou encaminhando o pedido para a área detentora da informação (CUNHA FILHO; XAVIER, 2014).

Paralelamente ao SIC físico, a CGU desenvolveu o Sistema Eletrônico do Serviço de Informação ao Cidadão (e-SIC), em cumprimento ao estabelecido na lei, como uma alternativa de encaminhamento de pedidos de acesso por meio da internet. Nesses termos, criou-se um sistema uniformizado, identificado através de um selo localizado nos portais institucionais dos órgãos da administração direta e indireta da União. O objetivo do portal do e-SIC é centralizar todas as solicitações de acesso à informação, funcionando como porta de entrada única para os pedidos, os quais são formalmente registrados e monitorados, possibilitando acompanhar sua evolução, as respostas e as denegatórias. Atualmente, o e-SIC também pode ser acessado por meio da plataforma federal "Fala.BR", que integrou os serviços de ouvidoria e acesso à informação em um mesmo site governamental. 
Para Michener, Contreras e Niskier (2018, p. 611), "a transparência passiva representa um 'teste mais exigente' dos compromissos com o acesso à informação pública”, dado que "obriga funcionários públicos a responder a demandas não antecipadas de informação de cidadãos em um determinado prazo", independentemente da agenda de prioridades do órgão.

No entanto, também nesse caso, atender ao pleito do cidadão não é, necessariamente, atuar de modo responsivo e transparente, visto que os dados podem ser manipulados, mediados por interesses de terceiros ou, simplesmente, percebidos como ininteligíveis pelos receptores (MICHENNER; BERSCH, 2011).

Nesse sentido, quem recebe a informação pode não conseguir compreendê-la e processá-la. Convergente a essa situação, Zuccolotto e Teixeira (2019, p. 40) comentam que "é possível que uma organização esteja disponibilizando seus documentos e procedimentos para acesso público e, contudo, não seja transparente, uma vez que a informação é percebida como incoerente pelos cidadãos".

\section{Procedimentos metodológicos}

Esta pesquisa caracteriza-se como aplicada, exploratória, descritiva e de abordagem qualitativa (CRESwell, 2010; GIL, 2017). A coleta de dados empregou sugestões de Creswell (2010), caracterizando-se como transversal, já que consistiu, dentro de um determinado período - janeiro e fevereiro de 2019 -, na análise dos portais das universidades, bem como no envio de formulários de solicitação de informação. Dessa forma, a pesquisa foi realizada em duas etapas, desenvolvidas de forma paralela. A Figura 1 ilustra resumidamente essas etapas:

\section{Figura 1 - Etapas da pesquisa}

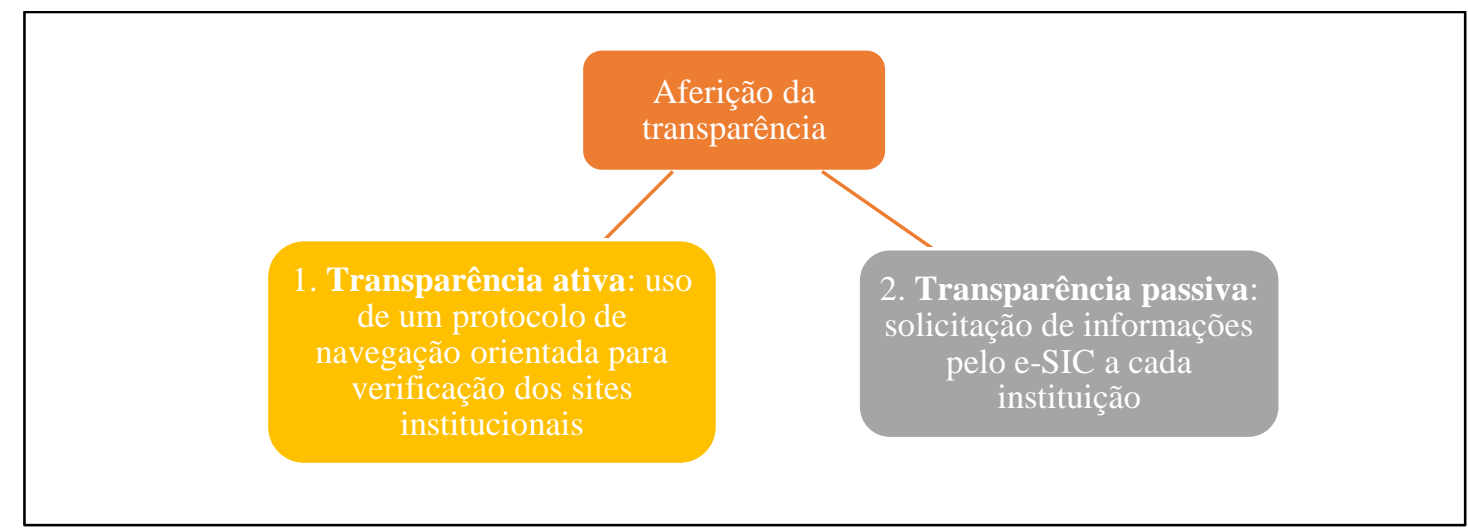

Fonte: Elaboração pelos autores. 
A primeira etapa do processo de coleta, referente à avaliação da transparência ativa, materializou-se por meio de observação direta e sistemática dos sites institucionais das 63 universidades, conforme perspectiva "midiática", estabelecida por Zuccolotto, Teixeira e Riccio (2015), tendo como parâmetro o Guia da CGU de 2017, com 12 itens de avaliação (expandidos para 18). A Figura 2 ilustra as fases do processo.

\section{Figura 2 - Etapas da pesquisa sobre transparência ativa}

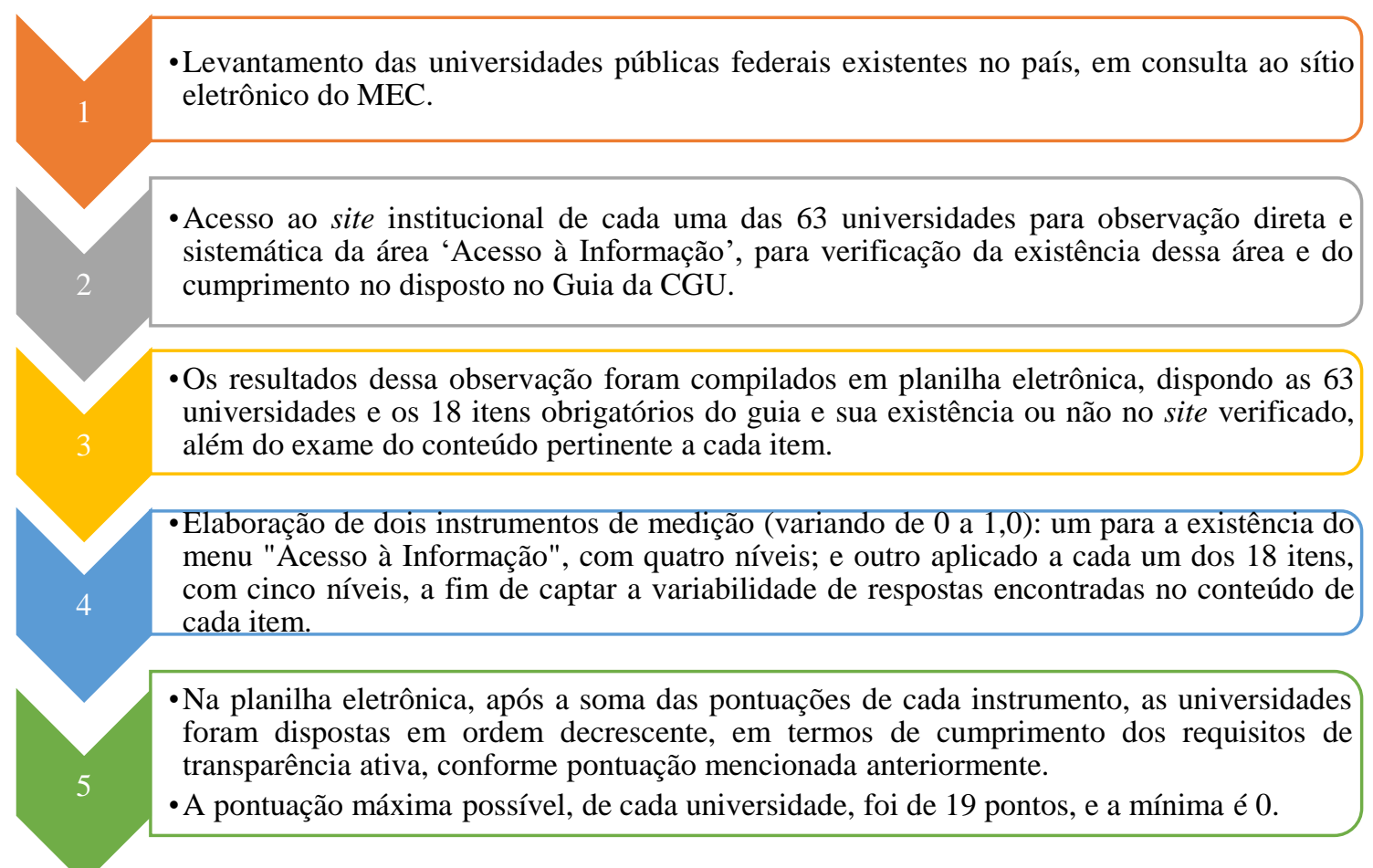

Fonte: Elaboração pelos autores.

O Guia da CGU, denominado Guia de transparência ativa para órgãos $e$ entidades do Poder Executivo federal (BRASIL, 2017b), foi utilizado como um protocolo de navegação orientada, empregado como parâmetro na observação sistemática dos sites das universidades. Ele estabelece que a divulgação ativa deve ser feita em uma seção específica denominada "Acesso à Informação", a ser disponibilizada como menu principal na página inicial do órgão. Esse menu deverá ser composto por, no mínimo, 12 itens (os quais são expandidos para 18), cuja nomenclatura e ordem são detalhadamente descritas no guia e foram empregadas como indicadores neste trabalho. São eles: Institucional (subdividido em sete itens); Ações e Programas; Participação Social; Auditorias; Convênios e Transferências; Receitas e Despesas; Licitações e Contratos; Servidores; Informações Classificadas; Serviço de Informação ao Cidadão; Perguntas 
Frequentes; e Dados Abertos. Desse modo, um total de 18 dimensões compuseram a avaliação de cada site institucional.

No entanto, durante o processo de coleta de dados, constatou-se que apenas a aferição da existência ou não de cada um desses itens não seria suficiente para captar a variabilidade das informações encontradas. A análise binária, com suas atribuições de 'SIM' e 'NÃO', mostrou-se insuficiente para analisar a diversidade do que foi descoberto e para lidar com os impasses que surgiram. Dessa forma, foram elaboradas duas escalas com pontuação variável: uma com quatro níveis, para tratar da estrutura do menu "Acesso à Informação"; e outra com cinco níveis, para cobrir a existência dos 18 itens e seu conteúdo. As Tabelas 1 e 2 detalham essas pontuações.

Tabela 1 - Escala de pontuação do menu "Acesso à Informação"

\begin{tabular}{|c|c|}
\hline Categorização & Pontuação \\
\hline $1-\mathrm{O}$ menu "Acesso à Informação" não existe. & 0,0 \\
\hline $\begin{array}{l}2 \text { - O menu "Acesso à Informação" não segue a estrutura do guia, mas existe sob outra } \\
\text { forma. }\end{array}$ & 0,25 \\
\hline $\begin{array}{l}3 \text { - O menu "Acesso à Informação" segue a estrutura do guia, mas ocorreu alguma das } \\
\text { seguintes situações: } \\
3.1 \text { - está desatualizado; } \\
3.2 \text { - está na forma retrátil; } \\
3.3 \text { - não está na página inicial da instituição. }\end{array}$ & 0,50 \\
\hline 4-O menu "Acesso à Informação" segue a estrutura do guia e está atualizado. & 1,0 \\
\hline
\end{tabular}
Fonte: Elaboração pelos autores.

Tabela 2 - Escala de pontuação do conteúdo do menu “Acesso à Informação"

\begin{tabular}{lc}
\hline \multicolumn{1}{c}{ Categorização } & Pontuação \\
\hline 1 - O item não existe. & 0,0 \\
\hline 2- O item existe, mas não contém informação alguma (o campo está vazio). & 0,25 \\
\hline 3 - O item existe, tem conteúdo, mas ocorreu uma ou mais das seguintes situações: & \\
3.1 - o conteúdo está incompleto, insuficiente ou num formato não amigável; & \\
3.2 - o link disponibilizado não funciona, dá erro; & 0,50 \\
3.3 - há um link para uma página externa, mas não há o passo a passo para localizar a & \\
informação; & \\
3.4 - a informação está desatualizada; & 0,75 \\
3.5 - o item tem informações fora de seu escopo. & 1,00 \\
\hline $4-$ O item existe, tem conteúdo pertinente, mas misturado com o teor de outros itens. & \\
\hline $5-$ O item existe, tem informação completa e pertinente. &
\end{tabular}
Fonte: Elaboração pelos autores. 


\section{Figura 3 - Etapas da pesquisa sobre transparência passiva}

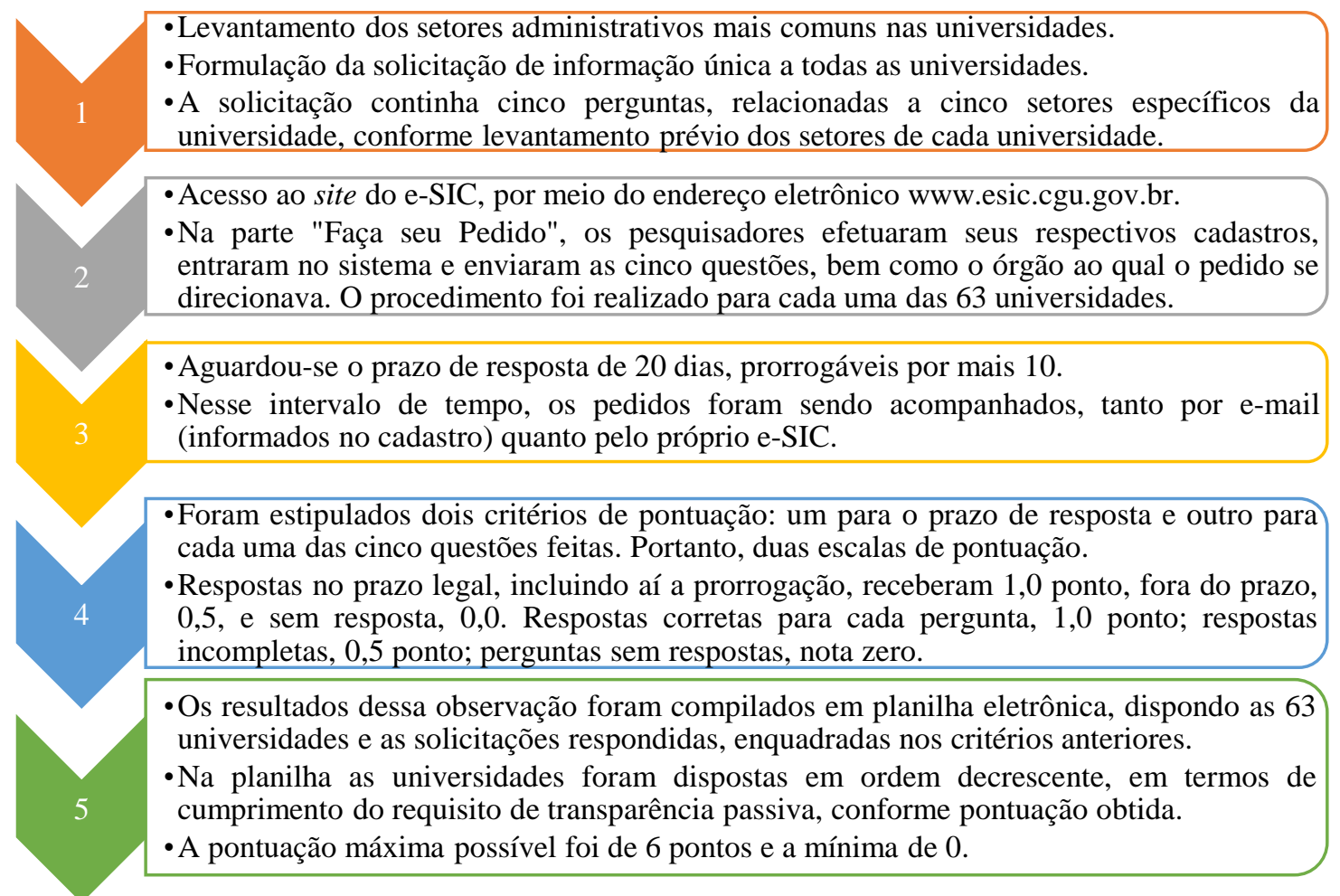

Fonte: Elaboração pelos autores.

A segunda etapa da pesquisa, referente à avaliação da transparência passiva, concretizou-se por meio do envio de solicitação de informação a cada uma das 63 universidades, por intermédio do e-SIC. A Figura 3 ilustra as fases do processo.

As cinco solicitações feitas às universidades foram perguntas totalmente relacionadas aos dados do cotidiano de trabalho de cada uma das áreas descritas no Quadro 3.

\begin{tabular}{ccl} 
Quadro 3 & Solicitações de acesso à informação às Pró-Reitorias \\
\hline $\mathbf{N}^{\mathbf{0}}$ & Pró-Reitoria & \multicolumn{1}{c}{ Solicitação de acesso à informação } \\
\hline 1 & Graduação & $\begin{array}{l}\text { Quantidade de alunos matriculados em 2018 na graduação e } \\
\text { quantidade de vagas ociosas, que não foram preenchidas ao longo do } \\
\text { ano. }\end{array}$ \\
\hline 2 & Extensão e cultura & $\begin{array}{l}\text { Quantidade de programas de extensão e respectivas quantidades de } \\
\text { alunos participantes no ano de 2018. }\end{array}$ \\
\hline 3 & $\begin{array}{c}\text { Pós-Graduação e } \\
\text { pesquisa }\end{array}$ & $\begin{array}{l}\text { Quantidade de programas de especialização, mestrado e doutorado e } \\
\text { respectivas quantidades de alunos matriculados no ano de 2018. }\end{array}$ \\
\hline 4 & Administração & $\begin{array}{l}\text { Quantidade de contratos vigentes em 2018 com empresas prestadoras } \\
\text { de serviços terceirizados com dedicação exclusiva de mão de obra } \\
\text { (limpeza, segurança, entre outras) e respectivos valores. }\end{array}$ \\
\hline 5 & $\begin{array}{c}\text { Planejamento, } \\
\text { orçamento e finanças }\end{array}$ & \begin{tabular}{l} 
Plano/Programa de Planejamento Institucional 2018. \\
\hline
\end{tabular}
\end{tabular}

Fonte: Elaboração pelos autores. 
Assim, após o registro de cada um dos 63 pedidos, ao longo dos 20 dias seguintes, as instituições foram respondendo e/ou solicitando prorrogação dos pedidos. Quase $40 \%$ das universidades solicitaram prorrogação de 10 dias, além dos 20 dias iniciais, conforme disposição contida no artigo $11, \S 2^{\circ}$ da lei. Ao mesmo tempo em que se recebiam as respostas, percebia-se que uma grande parcela de universidades não respondia conforme se conjecturara, razão pela qual apenas uma escala com pontuação para o prazo não abarcaria o rol de situações que estavam acontecendo. Concluiu-se que seriam necessários dois indicadores: um para o fator "prazo", e outro para o fator "conteúdo das respostas".

Essas questões são de suma importância no bojo da lei, e seus descumprimentos constituem motivos de recurso junto à CGU e de responsabilização do agente público, conforme disposições expressamente contidas na norma.

As Tabelas 3 e 4 detalham esses indicadores criados para o estudo.

Tabela 3 - Escala de pontuação quanto ao prazo de resposta da solicitação

\begin{tabular}{lc}
\multicolumn{1}{c}{ Categorização } & Pontuação \\
\hline $1-$ A solicitação não foi respondida. & 0,0 \\
\hline 2 - A solicitação não foi respondida no prazo legal $(20+10$ dias $)$. & 0,50 \\
\hline $3-$ A solicitação foi respondida no prazo legal $(20+10$ dias $)$. & 1,0 \\
\hline
\end{tabular}

Fonte: Elaboração pelos autores.

Tabela 4 - Escala de pontuação do conteúdo de cada uma das cinco perguntas

\begin{tabular}{lc}
\multicolumn{1}{c}{ Categorização } & Pontuação \\
\hline 1 - Resposta incompleta, pois ocorreu uma ou mais das seguintes situações: & \\
1.1 - o conteúdo está incompleto ou insuficiente; & \\
1.2 - o link disponibilizado não funciona, apresenta erro; & 0,50 \\
1.3 - há um link para uma página externa, mas não há o passo a passo para localizar a & \\
informação; & \\
1.4 - a informação está desatualizada; & \\
1.5 - os arquivos enviados são demasiado complexos e não amigáveis para se extrair a & \\
informação; & \\
1.6 - exigiu do solicitante interferir nos arquivos para obter a informação solicitada. & \\
\hline 2 - Resposta certa e completa & \\
\hline
\end{tabular}

Fonte: Elaboração pelos autores.

Apenas após a criação desse fluxo, as respostas foram avaliadas e suas respectivas notas lançadas em uma planilha. Ao final, os resultados foram somados e compilados, dispondo em ordem decrescente as 63 universidades, em termos de cumprimento do requisito de transparência passiva. 


\section{Análise e discussão dos resultados}

\subsection{Análise da transparência ativa}

Ao avaliar a transparência ativa nos sites das universidades, no que tange à estrutura do menu, apenas sete instituições cumpriram esse critério: Universidade Federal de Lavras (UFLA), Universidade Federal de Roraima (UFRR), Universidade Federal do Piauí (UFPI), Universidade Federal do Recôncavo da Bahia (UFRB), Universidade Federal do Tocantins (UFT), Universidade Federal do Triângulo Mineiro (UFTM) e Universidade Federal do Vale do São Francisco (UNIVASF). Como se percebe, são instituições das Regiões Sudeste (2), Norte (2) e Nordeste (3) do Brasil.

Nas outras 56 instituições, os pesquisadores tiveram de procurar nos respectivos sites outras formas nas quais esse conteúdo se apresentava, o que levou às ponderações identificadas e já mencionadas na seção anterior. Isso significa que quase $90 \%$ das instituições não seguiram as orientações do guia, de dispor um menu "Acesso à Informação", com 12 itens e na forma expandida na página inicial do órgão. Essas instituições não receberam a pontuação máxima de um ponto $(1,0)$ quanto ao cumprimento da existência de um menu "Acesso à Informação" estruturado em suas páginas iniciais. Suas pontuações variaram entre " 0 ”, “ 0,25 ” e “ 0,5 ”, conforme escala de pontuação anteriormente apresentada.

Sobre os 12 itens avaliados, expandidos para 18, a variabilidade de respostas foi enorme, resultando em pontuações que oscilaram entre " 0 ”, “ 0,25 ", “ 0,5 ", “ 0,75 ” e "1 1,0 ", por item, conforme escala de pontuação anteriormente descrita. Assim, antes de se extraírem os dados por universidade, efetuou-se a soma de todas as notas obtidas por cada item, para que fosse possível visualizar todos os itens e suas respectivas pontuações totais.

Itens com pontuações mais altas significam que tiveram mais notas iguais a 1,0, pois foram localizados dentro do menu "Acesso à Informação", e seu conteúdo continha informação completa e pertinente. Já itens com pontuações mais baixas significam que, ou não foram encontrados em algumas universidades, ou seu conteúdo se encaixa em algum dos critérios definidos, o que os fizeram receber pontuação variável entre "0" e “ 0,75 ”. A Tabela 5 contém um recorte da planilha e ilustra esse ponto. 
Tabela 5 - Pontuação de cinco universidades quanto ao item "Institucional"

\begin{tabular}{clcccc}
\hline & \multicolumn{2}{c}{ Dados da Universidade } & & \multicolumn{3}{c}{ Pontuação do “Item Institucional” } \\
\hline $\mathrm{N}^{\mathbf{o}}$ & \multicolumn{1}{c}{ Instituição } & Sigla & $\begin{array}{c}\text { Estrutura } \\
\text { organ. }\end{array}$ & $\begin{array}{c}\text { Telefones/ } \\
\text { Endereços }\end{array}$ & $\begin{array}{c}\text { Agenda de } \\
\text { autoridades }\end{array}$ \\
\hline $\mathbf{1}$ & Fundação Universidade Federal de Rondônia & UNIR & 0 & 0 & 0 \\
\hline $\mathbf{2}$ & Universidade Federal da Bahia & UFBA & 1 & 1 & 0,5 \\
\hline $\mathbf{3}$ & Universidade Federal da Fronteira Sul & UFFS & 0 & 0 & 0 \\
\hline $\mathbf{4}$ & Universidade Federal da Paraíba & UFPB & 1 & 1 & 0,5 \\
\hline $\mathbf{5}$ & Universidade Federal de Alagoas & UNIFAL & 1 & 0 & 0 \\
\hline & & Total & $\mathbf{3}$ & $\mathbf{2}$ & $\mathbf{1}$ \\
\hline
\end{tabular}

Fonte: Elaboração pelos autores.

Os dados da Tabela 5 exemplificam a soma efetuada por item, para as cinco universidades detalhadas. Assim, fica claro que o item "Estrutura Organizacional" obteve maior pontuação total, seguido de "Telefones/Endereços" e "Agenda de autoridades". Nesse recorte, três instituições (de cinco) continham a estrutura organizacional em seus menus de "Acesso à Informação", com conteúdo condizente com o estipulado no guia, razão pela qual receberam nota igual a "1,0" ponto. As outras duas instituições não continham esse item e, por essa razão, receberam nota zero. $O$ item "Agenda de autoridades", com menor pontuação total, foi encontrado em duas universidades, mas seu conteúdo ou estava incompleto, desatualizado, com link que não funcionava, ou qualquer outra situação estabelecida na Tabela 6 , no espectro coberto pela nota 0,5 .

Dessa forma, esse raciocínio se estendeu aos 12 itens e às 63 universidades. Assim, supondo que todas as 63 instituições tivessem determinado item, com conteúdo correto, esse item receberia pontuação igual a 1,0, e nota total igual a $63(63 \times 1,0=63)$, ou seja, a nota máxima possível de cada um dos 12 itens. No entanto, nenhum item atingiu esse valor. As notas abaixo de 1,0 foram conferidas aos itens com teor em desacordo com o estabelecido no protocolo de navegação orientada utilizado. A Figura 4 detalha a soma total de cada um dos 18 itens: 
Figura 4 - Pontuação total por item, em ordem crescente

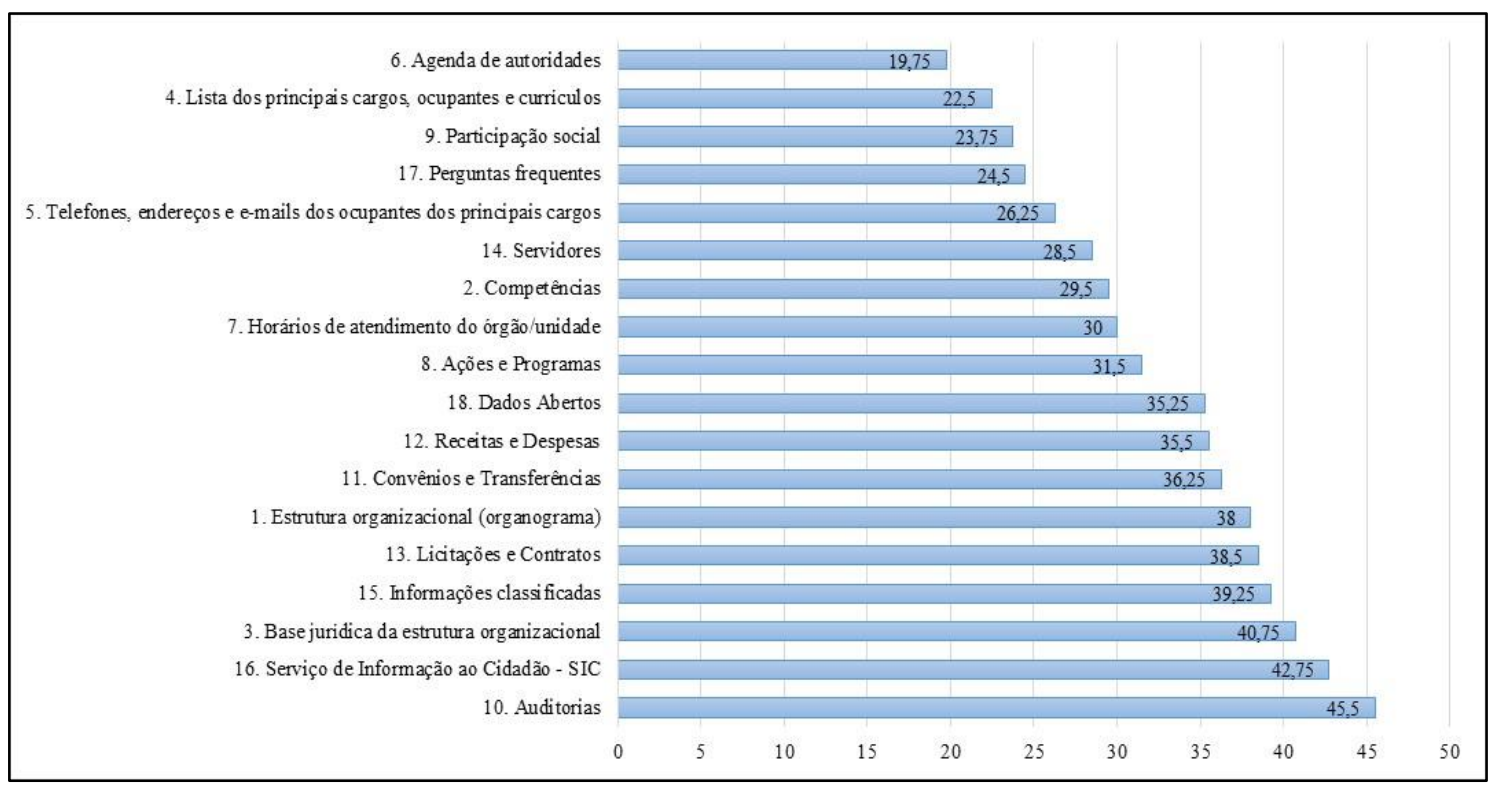

Fonte: Elaboração pelos autores.

Da Figura 4, percebe-se que exatamente metade dos itens tem pontuação máxima até 31,5, metade do valor máximo possível (63), o que aponta um descaso institucional disseminado por parte das universidades em relação a itens referentes a informações triviais, básicas para a população, como a agenda de autoridades, os cargos do órgão e telefones e endereços de contato. Essa questão, aliás, exemplificada pelo item 5 (telefones, endereços e e-mail), é incoerente com a razão da existência das próprias universidades, afinal, como as pessoas poderão obter informações atualizadas sobre os cursos da instituição se não conseguem contatá-la por meio do que veem em seu site?

A outra metade dos itens, em sua maioria de conteúdo mais sofisticado e com pontuação crescente, acima de 35,0, evidencia um esforço maior das instituições em prover informações mais atualizadas e completas, talvez em um esforço de também atender a órgãos de fiscalização mais incisiva, como o Tribunal de Contas da União (TCU).

Outro ponto relevante refere-se à composição da pontuação de cada item, como forma de aferir mais precisamente a quantidade de instituições que continham o item e qual o tipo de nota. A Figura 5 permite visualizar essa composição. 
Figura 5 - Composição da pontuação de cada item

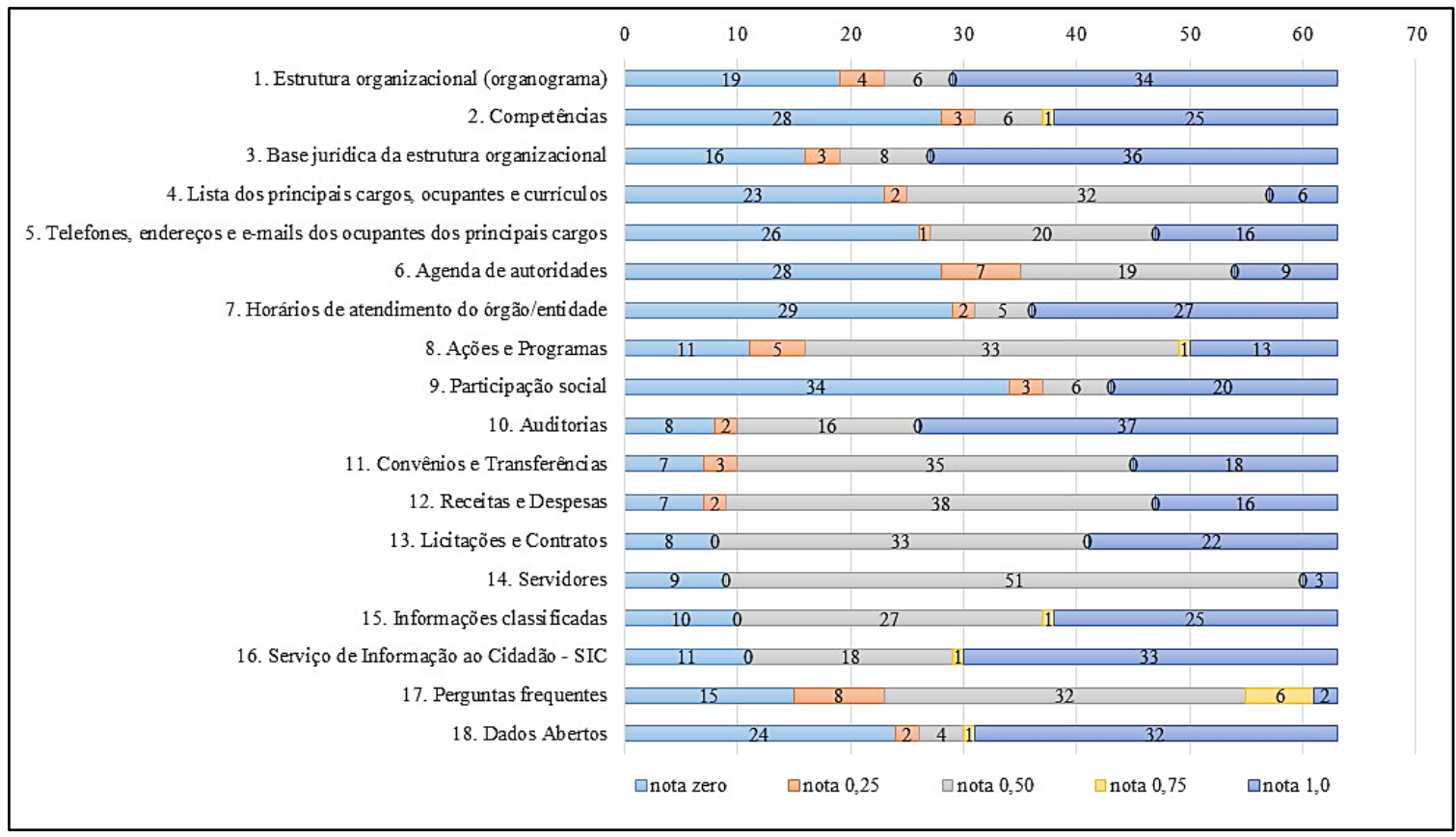

Fonte: Elaboração pelos autores.

Assim, por exemplo, quanto ao item 1, "Estrutura Organizacional" (normalmente materializada por um organograma), 19 universidades não tinham esse item (nota zero); quatro possuíam, mas o campo estava vazio, sem informações (nota 0,25); em seis havia algum conteúdo, mas não estava de acordo com o guia, ou seja, apresentava algum erro (nota 0,5 ); e 34 possuíam o item com conteúdo adequado (nota 1,0), totalizando 63 instituições.

A Figura 5 permite fazer ainda outras inferências. Percebe-se que há itens que simplesmente não existiam na maior parte das instituições, como "Participação Social", ausente em 34 universidades (54\%), mais da metade da população estudada; outros, como "Servidores", estavam presentes em 54 instituições, ou seja, em $86 \%$ da população, mas, na maior parte, o teor do item continha algum erro ou estava incompleto (81\%).

Esse retrato obtido pela pesquisa mostra que tornar a informação simplesmente existente, facilmente disponível e com conteúdo compatível e atualizado não é a regra, mas a exceção. Essa dinâmica persistente, após sete anos de existência da LAI, revela resquícios de uma cultura de sigilo, e não de uma cultura de abertura. Pois a informação, que pode ser ou não de interesse da sociedade, não é divulgada conforme a lei e outras normas associadas prescrevem. Portanto, o que se intui é que, apesar da existência de uma lei forte, ampla e importante, ainda há uma cultura de não prestação das informações. 
A Tabela 6, por restrições de espaço, apresenta uma síntese com o ranking da etapa da transparência ativa, exibindo, em ordem decrescente, as 10 universidades mais bem pontuadas.

Tabela 6 - Síntese da pontuação das universidades quanto à transparência ativa

\begin{tabular}{|c|c|c|c|c|c|}
\hline $\mathbf{N}^{\mathbf{o}}$ & Instituiçãa & Sigla & Estado & Região & Pontuação \\
\hline 1 & Universidade Federal da Paraíba & UFPB & Paraíba & Nordeste & 17,0 \\
\hline 2 & Universidade Federal do ABC & UFABC & São Paulo & Sudeste & 16,0 \\
\hline 3 & $\begin{array}{l}\text { Universidade Federal do Rio de } \\
\text { Janeiro }\end{array}$ & UFRJ & Rio de Janeiro & Sudeste & 15,75 \\
\hline 4 & Universidade Federal de Lavras & UFLA & Minas Gerais & Sudeste & 15,0 \\
\hline 5 & $\begin{array}{l}\text { Universidade Federal de Mato } \\
\text { Grosso }\end{array}$ & UFMT & Mato Grosso & Centro Oeste & 15,0 \\
\hline 6 & $\begin{array}{l}\text { Universidade Federal de Ouro } \\
\text { Preto }\end{array}$ & UFOP & Minas Gerais & Sudeste & 14,75 \\
\hline 7 & $\begin{array}{l}\text { Universidade Federal do } \\
\text { Triângulo Mineiro }\end{array}$ & UFTM & Minas Gerais & Sudeste & 14,5 \\
\hline 8 & $\begin{array}{l}\text { Universidade Federal do Estado } \\
\text { do Rio de Janeiro }\end{array}$ & UNIRIO & Rio de Janeiro & Sudeste & 14,25 \\
\hline 9 & $\begin{array}{l}\text { Universidade Federal Rural da } \\
\text { Amazônia }\end{array}$ & UFRA & Pará & Norte & 14,25 \\
\hline 10 & Universidade Federal de Goiás & UFG & Goiás & Centro Oeste & 13,75 \\
\hline$\ldots$ & Continua... & & & & \\
\hline
\end{tabular}

Fonte: Elaboração pelos autores.

Tendo como pontuação máxima possível o valor de 19,0, a média aritmética simples da população estudada, que se refere ao censo realizado, foi de 9,63. Das 63 instituições, as 36 primeiras posições tiveram pontuação acima dessa média, cerca de 57\% do total. A Universidade Federal da Paraíba (UFPB) foi a primeira colocada, com 17 pontos, a única representante da Região Nordeste entre as 10 primeiras. Em segundo ficou a Universidade Federal do ABC (UFABC), com 16 pontos e, em terceiro, a Universidade Federal do Rio de Janeiro (UFRJ), com 15,75, ambas da Região Sudeste, mas de estados diferentes.

A Tabela 7 exibe a quantidade de universidades por região, considerando as primeiras 36 colocadas, todas acima da média de 9,63: 
Tabela 7 - Regiões das 36 universidades pontuadas acima da média de 9,63

\begin{tabular}{|c|c|c|c|c|}
\hline Região & Estado(s) & Quantidade & Universidade(s) & Colocação(苂s) \\
\hline \multirow{4}{*}{ Centro-Oeste } & Brasília & 1 & UNB & 18 \\
\hline & Goiás & 1 & UFG & 10 \\
\hline & Mato Grosso & 1 & UFMT & 5 \\
\hline & Total & 3 & & \\
\hline \multirow{8}{*}{ Nordeste } & Alagoas & 1 & UFAL & 34 \\
\hline & Bahia & 2 & UFRB; UFSB & $17 ; 35$ \\
\hline & Ceará & 2 & UFC; UFCA & $11 ; 21$ \\
\hline & Ceará/Bahia & 1 & UNILAB & 29 \\
\hline & Paraíba & 1 & UFPB & 1 \\
\hline & Pernambuco/Bahia/Piauí & 1 & UNIVASF & 12 \\
\hline & Sergipe & 1 & UFS & 20 \\
\hline & Total & 9 & & \\
\hline \multirow{4}{*}{ Norte } & Pará & 3 & $\begin{array}{l}\text { UFRA; UNIFOPA; } \\
\text { UNIFESSPA }\end{array}$ & $9 ; 13 ; 24$ \\
\hline & Roraima & 1 & UFRR & 22 \\
\hline & Tocantins & 1 & UFT & 28 \\
\hline & Total & 5 & & \\
\hline \multirow{5}{*}{ Sudeste } & Espírito Santo & 1 & UFES & 16 \\
\hline & Minas Gerais & 8 & $\begin{array}{l}\text { UFLA; UFOP; } \\
\text { UFTM; UFSJ } \\
\text { UNIFAL; UFV } \\
\text { UFJF; UFVJM }\end{array}$ & $\begin{array}{c}4 ; 6 ; 7 ; 15 ; 24 \\
\quad 27 ; 30 ; 36\end{array}$ \\
\hline & Rio de Janeiro & 2 & UFRJ; UNIRIO & $3 ; 8$ \\
\hline & São Paulo & 3 & $\begin{array}{l}\text { UFABC; UFSCar } \\
\text { UNIFESP }\end{array}$ & $2 ; 14 ; 26$ \\
\hline & Total & 14 & & \\
\hline \multirow{3}{*}{ Sul } & Rio Grande do Sul & 3 & $\begin{array}{l}\text { FURG; UFSM } \\
\text { UFCSPA }\end{array}$ & $19 ; 31 ; 33$ \\
\hline & $\begin{array}{l}\text { Rio Grande do Sul/Santa } \\
\text { Catarina/Paraná }\end{array}$ & 1 & UFFS & 32 \\
\hline & Santa Catarina & 1 & UFSC & 25 \\
\hline
\end{tabular}

Fonte: Elaboração pelos autores.

Fazer um censo no qual um pouco mais da metade da população avaliada está acima da média estabelecida pressupõe que há dificuldades no cumprimento pleno da lei pelo grupo, pois não são casos isolados. A transparência ativa, mais detalhada na LAI que a transparência passiva, e objeto de um Guia especializado da CGU, representa uma faceta da transparência teoricamente mais acessível ao cidadão e dinâmica, disponível em tempo real a qualquer usuário. No entanto, conforme os resultados demonstram, o processo de divulgação ativa nesse grupo ainda carece de desenvolvimento e consolidação.

\subsection{Análise da transparência passiva}

No que se refere aos resultados, das 63 solicitações feitas, 49 foram respondidas no prazo final legalmente estipulado, o que representa cerca de $78 \%$ do total. As 14 solicitações restantes (22\%) englobaram os casos de: (i) seis respostas fora do prazo após 
solicitar prorrogação; (ii) duas respostas fora do prazo sem solicitar prorrogação; (iii) quatro sem respostas; e (iv) duas sem resposta após solicitar prorrogação, evidenciando não apenas falta de transparência, mas descumprimento da lei.

Dessa forma, 57 universidades responderam e apenas seis instituições ignoraram a solicitação, o que representa cerca de $9,5 \%$ dos pedidos. Foram elas: Universidade Federal do Amapá (UNIFAP), Universidade Federal do Oeste da Bahia (UFOB), Universidade Federal do Piauí (UFPI), Universidade Federal do Rio Grande (FURG), Universidade Federal do Rio Grande do Sul (UFRGS), e Universidade Federal Rural de Pernambuco (UFRPE). Coincidentemente, cinco dessas seis universidades ficaram entre as 27 com pontuação inferior à média de 9,63 da etapa da transparência ativa: UNIFAP (42 $2^{\mathrm{a}}$ posição), UFOB $\left(50^{\mathrm{a}}\right)$, UFPI (39 $)$, UFRGS $\left(40^{\mathrm{a}}\right)$ e UFRPE $\left(48^{\mathrm{a}}\right)$. Apenas a FURG ficou entre as 20 primeiras da etapa supracitada $\left(19^{a}\right)$.

No que diz respeito às cinco perguntas feitas na solicitação, a pontuação variou de pergunta para pergunta ao se somar as 57 respostas. As perguntas 4 e 5 , sobre contratos vigentes e planejamento institucional, respectivamente, foram as que obtiveram melhor pontuação, e juntas ficaram em primeiro lugar, com $82 \%$ cada uma. Isso quer dizer que $82 \%$ das instituições responderam corretamente a essas duas questões. No caso do planejamento institucional, as instituições ou enviaram seu arquivo de desenvolvimento institucional ou um link do documento, que direcionava à página institucional sobre o tema.

Já a pergunta 1, sobre alunos matriculados na graduação e vagas ociosas, obteve a menor pontuação: $61 \%$ foram consideradas respostas certas, com notas que variaram entre 1,0 e 0,5. As muitas instituições que não alcançaram pontuação máxima nessa questão, ou mesmo receberam nota zero, cometeram um dos seguintes erros: enviaram dados sobre alunos ingressantes na instituição, ou seja, os "calouros" que se tornaram alunos da universidade em 2018, o que não foi o conteúdo da pergunta; não enviaram as vagas ociosas; ou enviaram planilhas complexas e não amigáveis para a extração da informação pelo próprio solicitante, o que se mostrou incompatível com a simplicidade da informação solicitada.

A Tabela 8 apresenta a ordem com as perguntas que mais foram respondidas de modo correto, isto é, as perguntas que mais receberam nota igual a 1,0 e menos notas 0,5 e 0,0 , em uma pontuação máxima possível de 57, que foi o cenário dessa etapa. Nesse contexto, a média aritmética simples ficou em 43, o que deixa as perguntas 1 e 2 abaixo 
da média de acertos.

Tabela 8 - Pontuação acumulada de respostas do e-SIC

\begin{tabular}{|c|c|c|c|}
\hline Pró-Reitoria & Solicitação de acesso à informação & Pontos & Resposta (\%) \\
\hline $\begin{array}{l}\text { Planejamento, } \\
\text { orçamento e } \\
\text { finanças }\end{array}$ & $\begin{array}{l}\text { Pergunta 5: Plano/Programa de Planejamento Institucional } \\
2018 .\end{array}$ & 47 & 82 \\
\hline Administração & $\begin{array}{l}\text { Pergunta 4: Quantidade de contratos vigentes em } 2018 \text { com } \\
\text { empresas prestadoras de serviços terceirizados com dedicação } \\
\text { exclusiva de mão de obra (limpeza, segurança, entre outras) e } \\
\text { respectivos valores. }\end{array}$ & 47 & 82 \\
\hline Pró-Reitoria & Solicitação de acesso à informação & Pontos & Resposta (\%) \\
\hline $\begin{array}{l}\text { Extensão e } \\
\text { cultura }\end{array}$ & $\begin{array}{l}\text { Pergunta 2: Quantidade de programas de extensão e respectivas } \\
\text { quantidades de alunos participantes no ano de } 2018 \text {. }\end{array}$ & 42 & 74 \\
\hline Graduação & $\begin{array}{l}\text { Pergunta 1: Quantidade de alunos matriculados em } 2018 \text { na } \\
\text { graduação e quantidade de vagas ociosas, que não foram } \\
\text { preenchidas ao longo do ano. }\end{array}$ & 35 & 61 \\
\hline Média & & 43 & 75 \\
\hline
\end{tabular}

Fonte: Elaboração pelos autores.

A Tabela 9, seguindo a mesma lógica do tópico anterior, por restrições de espaço, apresenta uma síntese com o ranking da etapa da transparência passiva, exibindo, em ordem decrescente, as 11 Instituições de Ensino Superior (IES) mais bem pontuadas, e empatadas com a nota máxima.

Tabela 9 - Síntese da pontuação das universidades quanto à transparência passiva

\begin{tabular}{|c|c|c|c|c|c|}
\hline $\mathbf{N}^{\mathbf{o}}$ & Instituição & Sigla & Estado & Região & Pontuação \\
\hline 1 & $\begin{array}{lll}\text { Universidade } & \text { Federal } & \text { de } \\
\text { Alagoas } & & \end{array}$ & UFAL & Alagoas & Nordeste & 6 \\
\hline 2 & Universidade Federal de Goiás & UFG & Goiás & $\begin{array}{l}\text { Centro } \\
\text { Oeste }\end{array}$ & 6 \\
\hline 3 & Universidade Federal de Lavras & UFLA & Minas Gerais & Sudeste & 6 \\
\hline 4 & $\begin{array}{l}\text { Universidade Federal de Mato } \\
\text { Grosso do Sul }\end{array}$ & UFMS & $\begin{array}{l}\text { Mato Grosso do } \\
\text { Sul }\end{array}$ & $\begin{array}{l}\text { Centro } \\
\text { Oeste }\end{array}$ & 6 \\
\hline 5 & $\begin{array}{l}\text { Universidade Federal de São } \\
\text { João del-Rei }\end{array}$ & UFSJ & Minas Gerais & Sudeste & 6 \\
\hline 6 & Universidade Federal do Cariri & UFCA & Ceará & Nordeste & 6 \\
\hline 7 & Universidade Federal do Pampa & UNIPAMPA & Rio Grande do Sul & Sul & 6 \\
\hline 8 & $\begin{array}{l}\text { Universidade Federal do Rio } \\
\text { Grande do Norte }\end{array}$ & UFRN & $\begin{array}{l}\text { Rio Grande do } \\
\text { Norte }\end{array}$ & Nordeste & 6 \\
\hline 9 & $\begin{array}{l}\text { Universidade Federal do Sul e } \\
\text { Sudeste do Pará }\end{array}$ & UNIFESSPA & Pará & Norte & 6 \\
\hline 10 & $\begin{array}{l}\text { Universidade Federal Rural do } \\
\text { Semi-Árido }\end{array}$ & UFERSA & $\begin{array}{l}\text { Rio Grande do } \\
\text { Norte }\end{array}$ & Nordeste & 6 \\
\hline 11 & $\begin{array}{l}\text { Universidade } \text { Federal de } \\
\text { Ciências da Saúde de Porto } \\
\text { Alegre }\end{array}$ & UFCSPA & Rio Grande do Sul & Sul & 6 \\
\hline \multirow[t]{2}{*}{... } & Continua... & & & & \\
\hline & Média & & & & 4,25 \\
\hline
\end{tabular}

Fonte: Elaboração pelos autores. 
Dado que o valor máximo possível da nota foi de 6,0 pontos, a média aritmética da população estudada foi de 4,25. Esclarecendo que aqui a média calculada se refere ao resultado da soma dos dois critérios desta etapa: resposta no prazo e conteúdo de cada uma das cinco perguntas.

Verificou-se que as 45 primeiras posições tiveram pontuação acima da média de 4,25 , cerca de $71 \%$ do total e, conforme mencionado, 11 universidades compartilharam a primeira colocação, todas com a nota máxima: 6,0 pontos. Nessa mesma linha seguiram as pontuações seguintes, em poucos blocos, cada um com várias instituições: 12 instituições obtiveram nota 5,5; 13 universidades com nota 5,0; e nove com a nota de 4,5.

Quando se analisa o desempenho por região, percebe-se que a Região Sudeste empatou com a Região Nordeste na quantidade de universidades acima da média de 4,25, seguidas das Regiões Sul, Norte e Centro-Oeste. Mas, ao se considerar as 18 universidades abaixo da média (29\%), o Nordeste fica ligeiramente à frente do Sudeste, por ter uma instituição a menos nesse rol. As Regiões Centro-Oeste, Norte e Sul também apresentam menos universidades entre as últimas - 18 em relação às suas respectivas quantidades acima da média.

A Figura 6 ilustra a comparação entre as pontuações acima e abaixo da média (4,25 pontos) da quantidade de universidades de cada Região, considerando o total de instituições existentes, confrontando três variáveis.

Figura 6 - Comparação entre as regiões: pontuações acima e abaixo da média e total de universidades

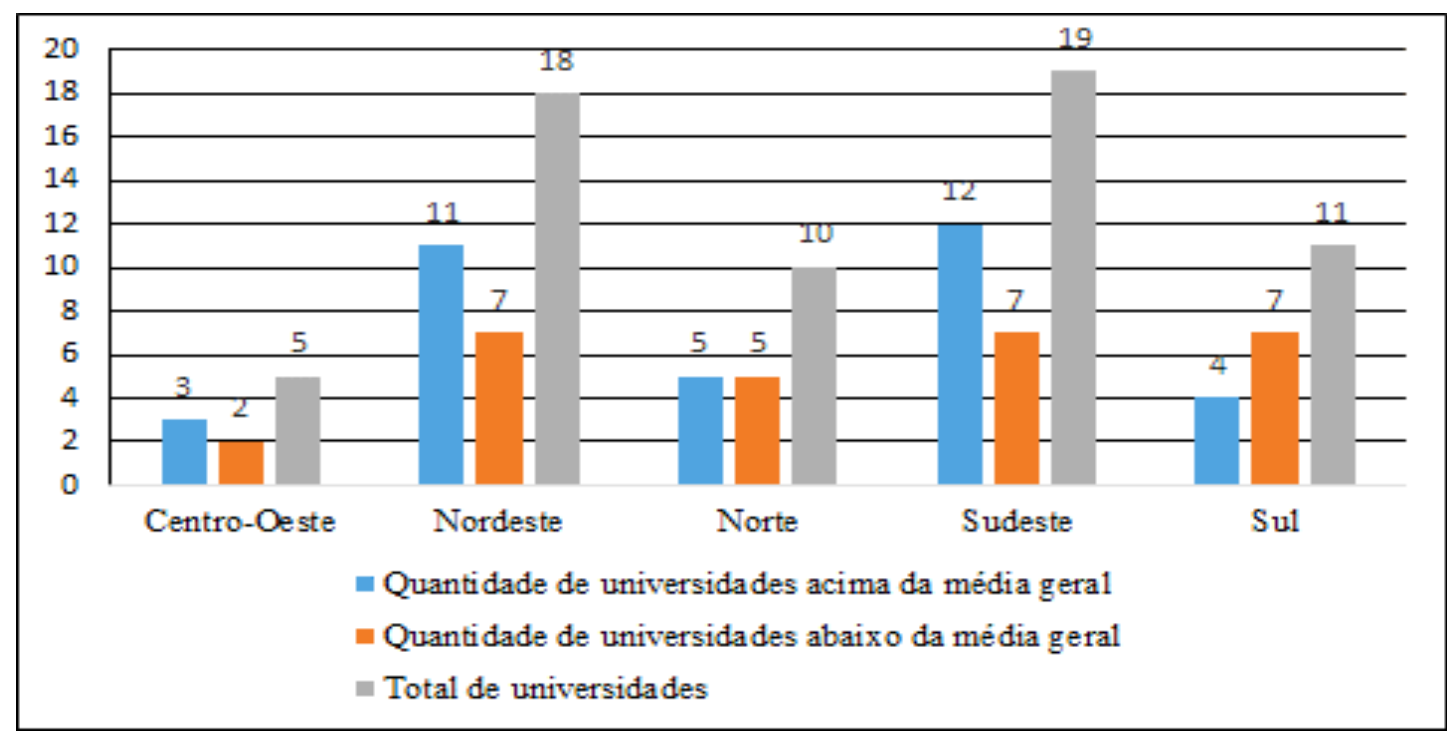

Fonte: Elaboração pelos autores. 


\section{Considerações finais}

Este trabalho teve por objetivo analisar se as universidades federais do Brasil são transparentes, sob as lentes da Lei de Acesso à Informação. Para isso, o objetivo central da pesquisa fora avaliar as transparências ativa e passiva de todas as universidades públicas federais brasileiras.

Nesse contexto a LAI foi abordada, seus artigos diretamente relacionados à pesquisa esmiuçados, e um grupo da administração pública focado: as universidades públicas federais.

Em termos de resultados, a avaliação da transparência ativa de todas as universidades federais revelou a existência de um longo caminho a ser percorrido, já que o guia da CGU utilizado como protocolo de navegação orientada não vem sendo cumprido em sua íntegra. Em virtude da falta de padronização das universidades, obtevese um corpus de dados heterogêneo, cujo tratamento exigiu a construção de instrumentos apropriados. Consequentemente, o resultado foi que cerca de um pouco mais da metade das universidades (57\%) obtiveram pontuação que as classificaram como acima da média no quesito da transparência ativa.

Talvez essa situação tenha ocorrido por desconhecimento do Guia da CGU, por falta de capacitação e treinamento de servidores quanto à aplicação da LAI na instituição, ou mesmo por não existir o devido reconhecimento da importância desse tipo de transparência pela alta gestão da universidade. O fato é que o próprio menu "Acesso à Informação", canal imprescindível por onde o órgão público deve fornecer um rol de informações à sociedade, não existia em cerca de $90 \%$ das universidades. Além disso, em $46 \%$ dos sites institucionais pesquisados, não foram encontradas informações triviais sobre um órgão público que presta serviços diretamente à sociedade, como endereço, horários e telefones de contato.

Em relação aos resultados da transparência passiva, a maior parte das 63 universidades pesquisadas respondeu aos pedidos. Indubitavelmente, as universidades parecem comprometidas com a transparência passiva, e os dados revelaram alta porcentagem de respostas dentro do censo realizado. Mas o modo como as respostas vieram levantou outras questões, revelando aspectos até então ocultos, como a interpretação errônea do que foi perguntado ou o envio de inúmeros arquivos, em formatos variados, complexos e não amigáveis para perguntas consideradas básicas e simples. Em outras palavras, parte das instituições parecia desejar "pecar pelo excesso", 
em uma visão equivocada de que ser transparente se resume a enviar o maior número possível de arquivos como resposta ao solicitante, sejam eles compreensíveis ou não.

Essa situação significa que o órgão demandado teve a intenção de ser transparente, de cumprir com a lei, mas efetivamente não foi bem-sucedido ao fazê-lo, constituindo o que Heald (2006) denomina de transparência nominal: quando a informação é apenas divulgada/enviada/respondida, sem a preocupação primordial de que seja compreendida pelo cidadão de forma satisfatória e efetiva.

Diante desse quadro, também foi necessário criar indicadores, dispostos em uma escala de pontuação, que se adequassem ao material que se recebia, visto que "responder no prazo" não era mais o único critério que deveria ser pontuado. O resultado foi que, nessa etapa, a quantidade de universidades acima da média estabelecida foi maior que na etapa anterior: 45 instituições, cerca de $71 \%$ do grupo.

Dessa forma, considerando como parâmetros todos os instrumentos, etapas e procedimentos descritos nesse trabalho, foi possível atender ao objetivo definido e responder à pergunta inicial: as universidades federais podem ser consideradas transparentes, mas dependendo da ótica analisada, são mais transparentes sob um prisma do que sob outro. Essa constatação revela que não há sinergia institucional quando se trata de promover a transparência nas duas vertentes aqui analisadas: ativa e passiva. Isto é, cada tipo de transparência parece ser conduzido por setores diferentes, que não conversam entre si, estabelecendo uma política uníssona para a implementação de ações globais de transparência.

Nesse sentido, tendo em mente o que Silva et al (2014) mencionam acerca da heterogeneidade entre órgãos e entidades da administração pública federal, quando se avalia o nível de abertura, neste estudo em particular foi possível identificar, na verdade, uma heterogeneidade intrainstitucional, que se repetiu em diversas universidades. Ou seja, parece que as instituições pesquisadas ainda não percebem os dois canais de acesso à informação como "faces de uma mesma moeda", que demandam investimentos, treinamentos e alinhamento de ações de forma conjunta.

No caso concreto, a aferição da transparência passiva resultou em um índice de $71 \%$ da população, enquanto o índice da transparência ativa foi de 56\%. Essa diferença entre os tipos de transparência estudados aqui revela que, apesar dos obstáculos envolvidos no pedido de informação e das muitas respostas inadequadas obtidas, responder ao cidadão foi considerado, pelas instituições, mais relevante do que 
disponibilizar informações predeterminadas no site.

Os resultados também revelam a existência de um longo caminho a ser percorrido, evidenciando preocupações, sobretudo por dois motivos: (1) quando se considera todo o arcabouço normativo existente no país no que se refere ao direito de acesso à informação, principalmente após a CF/88, e corroborado pela promulgação da LAI; (2) os compromissos formais firmados pelos governos brasileiros na última década com a comunidade internacional no que diz respeito a práticas de transparência, como a Open Government Partnership

Essa realidade ambígua revelada pelos resultados evidencia a existência de uma transparência formal, amparada por lei, decretos e manuais, que, na prática, não é necessariamente real, dado que, nos mecanismos existentes de interação virtual, proporcionada tanto pelo e-SIC quanto pelos sites institucionais de cada universidade, tal transação não é bem-sucedida. E, no caso em tela, mostrou-se inclusive assimétrica, ao que Mendieta (2012) denomina como transparência opaca, uma pseudotransparência, na qual a finalidade não é ajudar o cidadão a controlar e a conhecer o governo, mas, sim, passar a imagem de que o governo está aberto, criar uma "ilusão de transparência". Essa "ilusão de transparência" é mencionada por Heald (2006), sendo resultado da divergência entre a transparência nominal e a transparência efetiva, mencionada em parágrafo anterior.

Assim, a partir do panorama delineado para as transparências das 63 universidades federais, foi possível extrair outra importante conclusão: a inferência de que não há relação entre as transparências. Em outras palavras, uma instituição que obteve boa pontuação na transparência ativa, não obteve, necessariamente, boa nota na transparência passiva, revelando que não há relação entre as transparências. Observou-se, por exemplo, que as 11 primeiras colocadas na etapa da transparência passiva não foram necessariamente as primeiras colocadas na transparência ativa, e vice-versa.

Em situações isoladas, uma ou outra instituição até apareceu nos dois rankings nas primeiras posições, mas a maioria ficou longe das primeiras colocações, tendo até instituição na penúltima posição em uma etapa, e ficando como uma das primeiras em outra. De modo geral, o fato de uma instituição ter sido bem colocada em uma transparência não a qualificou automaticamente para os primeiros lugares na outra. 
A mesma instituição obter pontuações tão distantes em cada etapa sugere que a transparência da instituição, como um todo, não é tratada por um único setor responsável. Sabe-se que a transparência passiva, em geral, fica a cargo da Ouvidoria do órgão ou do próprio e-SIC físico existente (QUINTÃO, 2019), mas a transparência ativa, a divulgação dos dados da instituição na internet, em seção própria de "Acesso à Informação", não necessariamente é supervisionada pelos setores supramencionados. Infere-se que o nível de transparência ainda depende da ação isolada de pessoas e setores, não sendo institucionalmente orquestrado.

Essa conjuntura reforça o entendimento presumido de que, quando se trata de analisar separadamente os tipos de transparência existentes em um mesmo órgão público, os resultados podem ser totalmente opostos, indicando uma falha institucional em tratar o assunto de forma completa e unificada. Ou seja, transparência ainda não é um compromisso institucionalizado e conduzido de forma alinhada por um único setor, como o são outras questões institucionais, revelando uma heterogeneidade interna no tratamento e na divulgação de informações.

Portanto, este trabalho mostra-se relevante, inédito e original, principalmente ao realizar uma avalição abrangente de transparência pública de uma determinada população de autarquias da administração pública federal sob as duas iniciativas previstas na LAI. Desse modo, a pesquisa teve um caráter censitário, pois pesquisou todas as universidades federais do território nacional, sendo capaz de, ao final, proporcionar um verdadeiro "raio-x" dessas instituições. Além disso, o trabalho mostra-se relevante e útil aos gestores públicos, em especial pelos indicadores criados no processo de avaliação de cada etapa, que podem ser replicados a outras instituições governamentais, dado que se baseiam em normas preexistentes, como a LAI e o guia da CGU, as quais são aplicáveis aos órgãos do Poder Executivo federal.

Naturalmente, a construção desta pesquisa apresenta algumas limitações. A primeira limitação refere-se à celeridade das mudanças das novas tecnologias de informação e das próprias informações e serviços disponibilizados nos portais, cada vez mais dinâmicos e demandados pela sociedade. Conforme Cruz, Silva e Spinelli (2016) verificaram, a promoção de uma transparência governamental também se concretiza através de um ininterrupto aprimoramento do site, o que pode ter ocorrido durante o período de levantamento dos dados para esta pesquisa. Outra limitação refere-se aos meses em que a coleta de dados da pesquisa foi realizada: janeiro e fevereiro de 2019. 
Usualmente, nesses meses, a maior parte do corpo de servidores das universidades está em férias, o que pode ter impactado a qualidade e o atendimento das solicitações no eSIC.

Como oportunidade de estudos futuros, orienta-se o aprofundamento da pesquisa em cinco temas: (1) repetição de toda a pesquisa nas demais instituições de ensino superior ligadas ao MEC, mas não abarcadas aqui, como as universidades estaduais, municipais e os institutos federais com cursos de nível superior; (2) análise da influência do fator geográfico nas instituições com maior pontuação e nas de menor pontuação - por exemplo: "por que as universidades da Região Sudeste foram as melhores classificadas em todas as transparências?"; (3) aplicação das escalas criadas a outros órgãos da esfera federal.

\section{Referências}

Afonso, P.; Vianna, H.; Mattos, J. Mecanismos de transparência pública e participação social adotados pela Universidade Federal de Pelotas com vistas ao cumprimento dos requisitos de transparência previstos na LAI. In: WORKSHOP DE TRANSPARÊNCIA EM SisTEMAS - WTRANS 2019, 2019, Belém, Pará. Anais. Belém, 2019.

Bairral, M. A. da C.; Silva, A. H. C.; Alves, F. J. dos S. Transparência no setor público: uma análise dos relatórios de gestão anuais de entidades públicas federais no ano de 2010. Revista de Administração Pública, v. 49, n. 3, p. 643-675, 2015.

BALL, C. What is transparency? Public Integrity, v. 11, n. 4, p. 293-307, 2009.

BRASIL. Constituição da República Federativa do Brasil de 1988. 1988. Disponível em: http://www.planalto.gov.br/ ccivil _ 03 / Constituicao/Constituicao.htm. Acesso em: 02 jul. 2017.

Decreto $n^{\circ}$ 9.203, de 22 de novembro de
$2017 \mathrm{a}$. Disponível em: http://www.planalto.gov.br/ccivil_03/_ato20152018/2017/decreto/D9203.htm. Acesso em 10 abr. 2020

Guia de publicação ativa nos sítios eletrônicos dos órgãos e entidades do Poder
Executivo Federal. 2017b. Disponível em: http://www.acessoainformacao.gov.br/lai-parasic/sic-apoio-orientacoes/guias-eorientacoes/gta-5a-versao.pdf. Acesso em: 10 jan. 2019.

Guia da política de governança pública.
Disponível https://www.gov.br/casacivil/pt-br/centrais-deconteudo/downloads/guia-da-politica-degovernanca-publica. Acesso em: 10 abr. 2020.

Lei $n^{o}$ 12.527, de 18 de novembro de 2011. 2011. Disponível em: http://www.planalto.gov.br/ccivil_03/_ato20112014/2011/Lei/ L12527.htm. Acesso em: 02 jul. 2017.

Relatório sobre a implementação da Lei $n^{o}$ 12.527/2011: Lei de Acesso à Informação. $2018 . \quad$ Disponível em http://www.acessoainformacao.gov.br/centralde-conteudo/publicacoes/relatorio-2017web.pdf. Acesso em: 10 jan. de 2019.

CONSElHo NAcional DE JustiçA (CNJ). Resolução no 260 de 11 de setembro de 2019. Altera a Resolução CNJ n. 215, de 16 de dezembro de 2015, e institui o ranking da Transparência do Poder Judiciário. Diário da Justiça Eletrônico/CNJ, no 173/2018, de 13 de setembro de 2018, p. 2-18. 
CReswell, J.W. Projeto de pesquisa: métodos qualitativo, quantitativo e misto. 3. ed. Porto Alegre: Artmed, 2010.

Cruz, M. do C. M. T.; Silva, T. A. B.; SPINElli, M. V. O papel das controladorias locais no cumprimento da Lei de Acesso à Informação pelos municípios brasileiros. Cadernos EBAPE.BR, v. 14, n. 3, p. 721-743, 2016.

Cunha FILho, M. C.; XAVIER, V. C. S. Lei de Acesso à Informação: teoria e prática. Rio de Janeiro: Lumen Juris, 2014.

FARIZA, I. Frustação com democracia cresce na América Latina. Jornal O Globo, Rio de Janeiro, p. 45, 25 mar. 2018.

Gama, M. C. F. da; Mattos, C. A. C. de; Aguiar, A. L. C. A Cultura organizacional e o direito à informação. Encontros Bibli: revista eletrônica de biblioteconomia e ciência da informação, Florianópolis, v. 24, n. 55, p. 1-22, 2019.

GIL, A. C. Como elaborar projetos de pesquisa. 6. ed. São Paulo: Gen/Atlas, 2017.

Guerra, M. das G. G. V.; Carvalho, K. de A. G. Transparência pública e acesso à informação: a utopia virando realidade na UEPB. Comunicação \& Informação, v. 22, p. 1-19, 2019.

HEALD, D. Varieties of transparency. In: HoOD, C.; HeAlD, D. (Eds.). Transparency: the key to better governance? New York: Oxford University Press, 2006. p. 25-43.

HooD, C. Transparency in historical perspective. In Hood, C.; HeAlD, D. (Eds.). Transparency: the key to better governance? New York: Oxford University Press, 2006. p. 3-23.

LEHER, R. A universidade reformada: atualidade para pensar tendências da educação superior 25 anos após sua publicação. Revista Contemporânea de Educação, vol. 8, n. 16, p. 316-340, 2013.

LIMA, M. P. Transparência pública e a Lei de Acesso à Informação no Brasil: uma análise dos estudos empreendidos durante os 5 anos de vigência da lei (2012-2017). In: ENCONTRO DA ANPAD - ENANPAD 2018, 42., 2018, Curitiba, Paraná. Anais. Curitiba: Anpad, 2018.

MACIEL, R. G.; FonsecA, P. G.; DUARTE, F. R.; SANTOS, E. M. dos. Sistema Eletrônico do
Serviço de Informação ao Cidadão (e-SIC) e sua contribuição para a transparência: uma experiência gerencial em uma universidade federal. Perspectivas em ciência da informação, Belo Horizonte, v. 24, n. 2, p. 143-164, 2019.

MCDERMOTT, P. Building open government. Government Information Quarterly, v. 27, p. 401-413, 2010.

MARIÑEZ NAVARRO, F. El debate abierto del gobierno abierto. In: CONGRESO INTERNACIONAL DEL CLAD SOBRE LA REFORMA DEL ESTADO Y DE LA ADMINISTRACIÓN PÚBliCA, 17., 2012, Cartagena, Colômbia. Anais. Cartagena: Clad, 2012.

Meijer, A. J.; Curtin, D.; Hillebrandt, M. Open government: connecting vision and voice. International Review of Administrative Sciences, v. 78, n. 1, p. 10-29, 2012.

Mendes VieIRA, K.; Pegoraro, D.; SÂMara VISENTINI, M. Percepção de transparência nas instituições de ensino: proposição e validação de instrumento. Revista de Educação e Pesquisa em Contabilidade $(\mathrm{REPeC})$, v. 14, n. 1, p. 34-55, 2020.

MendiETA, M. V. Transparencia y valor de la transparência. Marco conceptual. In: AsENSIO, R. J.;ÁlVAREZ, J. L.;MENDIETA, M. V. (Orgs.). La transparencia en los Gobiernos locales: una apuesta de futuro. Madrid: Fundación Democracia y Gobierno Local, 2012.

Michener, G.; Bersch, K. Conceptualizing the quality of transparency. Political Concepts, v. 49, p. 1-27, 2011.

Michener, G.; CONTRERAS, E.; NiSKIER, I. Da opacidade à transparência? Avaliando a Lei de Acesso à Informação no Brasil cinco anos depois. Revista de Administração Pública, v. 52, n. 4, p. 610-629, 2018.

MoRENO, A. C. $90 \%$ das universidades federais tiveram perda real no orçamento em cinco anos; verba nacional encolheu 28\%. 2018. Disponível em https://g1.globo.com/educacao/noticia/90das-universidades-federais-tiveram-perda-realno-orcamento-em-cinco-anos-verba-nacionalencolheu-28.ghtml. Acesso em: 01 jul. 2018.

Moura, I. C. de; GonçAlves, M. J. A. Acesso à informação e transparência nos portais dos institutos federais de educação do Brasil. In: CONFERÊNCIA DA ASSOCIAÇÃ̃O PORTUGUESA DE SISTEMAS DE INFORMAÇÃO - CAPSI 2019, 19., 
2019, Lisboa, Portugal. Anais. Lisboa: Apsi, 2019

Novelino, R. Corte no MEC afetará $18,2 \%$ do orçamento das universidades federais de todo o país para 2021, diz Andifes; entidade vê risco à pesquisa e ao ensino. 2020. Disponível em https://g1.globo.com/pe/pernambuco/noticia/20 20/08/10/corte-no-mec-afetara-182percent-doorcamento-das-universidades-federais-de-todoo-pais-para-2021-diz-andifes-entidade-ve-riscoa-pesquisa-e-ao-ensino.ghtml. Acesso em: 11 ago. 2020.

Pecegueiro, C. A.; Cordeiro, L. S. A Lei de Acesso à Informação nas universidades públicas do Estado do Maranhão: uma análise do ambiente digital. In: CONGRESSO BRASILEIRO DE BIBLIOTECONOMIA E DOCUMENTAÇÃO - CBBD 2019, 28., 2019, Vitória, Espírito Santo. Anais. Vitória, 2019.

POLÍZIO JÚNIOR, V. Lei de Acesso à Informação: manual teórico e prático. Curitiba: Juruá Editora, 2015.

QUINTÃO, T. Reflexões e dilemas sobre a ouvidoria pública no Brasil: uma análise das ouvidorias do Poder Executivo federal. Revista do Serviço Público, v. 70, n. 2, p. 297- 324, 2019.

Rosa, T.; BAPTAGLIN, L. Realidade e perspectivas de acesso aos bens documentais e à informação nas Ifes do Estado de Roraima. InCID: Revista de Ciência da Informação $e$ Documentação, v. 10, n. 1, p. 184-200, 2019.

RosA, T. C.; CABERo, M. M. M. A transparência ativa das Ifes brasileiras que ofertam a graduação em Arquivologia. Informação \& Sociedade: Estudos, v.29, n.4, p. 251-272, 2019.

RAupP, F. M.; PINHO, J. A. G. Review of passive transparency in Brazilian city councils. Revista de Administração da USP, São Paulo, v. 51, p. 288-298, 2016.

Rodrigues, D.; Resende, P.; CARneIRo, D. Análise da transparência pública em universidades federais: uma abordagem qualitativa à luz da Lei de Acesso à Informação. In: CONGRESSO ÍBERO-AMERICANO DE INVESTIGAÇÃO QUALITATIVA 2019 - CIAIQ 2019, 8., 2019, Lisboa, Portugal. Anais. Lisboa, 2019.
Silva, C. F. da; VAZ, W.; SANTOS, E. M. F. dos; BAlANiUK, R.; ChAVES, M. C. Dados abertos: uma estratégia para o aumento da transparência e modernização da gestão pública. Revista do Tribunal de Contas da União, Brasil, v. 46, n. 131, p. 22-29, 2014.

Silva, W. A. O.; BRUNI, A. L. Variáveis socioeconômicas determinantes para a transparência pública passiva nos municípios brasileiros. Revista de Administração Pública, v. 53, n. 2, p. 415-431, 2019.

TOLBERT, C. J.; Mossberger, K. The effects of E-Governance on trust and confidence in government. Public Administration Review, v. 22, n. 4, p. 354-369, 2006.

VIEIRA, C. do N.; DAHER, D. da M. A Lei de Acesso à Informação: uma análise dos sítios baseada na transparência ativa, nos centros e institutos federais de educação, ciência e tecnologia do Sudeste brasileiro. Brazilian Journal of Business, v. 2, n. 3, p. 2171-2192, 2020.

Weizenmann, F. B. de A.; Techio, J. W.; Pinto, N. G. M. O cumprimento da lei de acesso à informação no Instituto Federal de Educação Ciência e Tecnologia Farroupilha - IFFar. Revista Contribuciones a las Ciencias Sociales, v.13, n. 7, p. 1-17, 2020.

YAZIGI, A. F. Dinero, política y transparencia: el imperativo democrático de combatir la corrupción. INTERNATIONAL ANTI-CORRUPTION CONFERENCE (IACC), Durban, África do Sul, 1999. Anais. Duban, 1999. p. 10-15.

YU, H.; RobInson, D. G. The new ambiguity of "Open Government". UCLA Law Review Discourse, n. 59, p. 178-208, 2012.

Zuccolotto, R.; TeIXeIRA, M. A. C.; Riccio, E. L. Transparência: reposicionando o debate. Revista Contemporânea de Contabilidade, v. 12, n. 25, p. 137-158, 2015.

Zuccolotto, R.; TeIXeIRA, M. A. C. Transparência: aspectos conceituais e avanços no contexto brasileiro. Brasília - DF: Enap, 2019. 


\section{Melina Pompeu de Lima}

iD http://orcid.org/0000-0001-7017-5138

Mestre em Administração pela Universidade Federal Fluminense (UFF). Administradora no CEFET-RJ.

E-mail: melinapompeu@gmail.com

\section{Márcio Moutinho Abdalla}

(iD http://orcid.org/0000-0002-2607-1021

Doutor em Administração pela EBAPE/FGV. Professor do PPGA-UFF / Mestrado Profissional em Administração.

E-mail: marcioabdalla@id.uff.br.

\section{Leonel Gois Lima Oliveira}

\section{iD https://orcid.org/0000-0003-3876-5028}

Doutor em Administração pela EBAPE/FGV. Professor da Esmec (Escola Superior de Magistratura do Estado do Ceará) e da Unichristus (Centro Universitário Christus).

E-mail: leonelgois@tjce.jus.br 